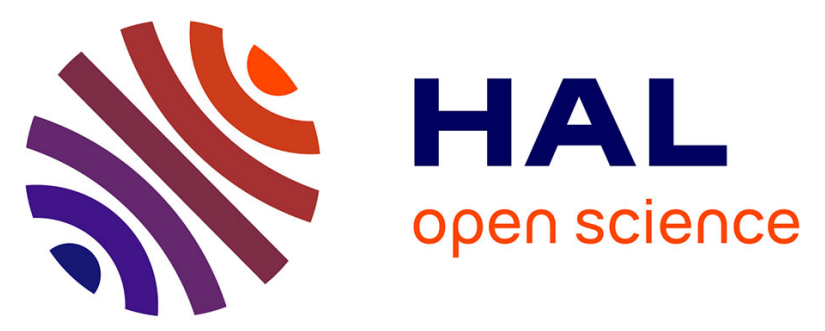

\title{
Resolving the Framework Position of Organic Structure-Directing Agents in Hierarchical Zeolites via Polarized Stimulated Raman Scattering
}

Guillaume Fleury, Julian Steele, I.C. Gerber, Franck Jolibois, Pascal Puech, Koki Muraoka, Sye Hoe Keoh, Watcharop Chaikittisilp, Tatsuya Okubo, Maarten Roeffaers

\section{To cite this version:}

Guillaume Fleury, Julian Steele, I.C. Gerber, Franck Jolibois, Pascal Puech, et al.. Resolving the Framework Position of Organic Structure-Directing Agents in Hierarchical Zeolites via Polarized Stimulated Raman Scattering. Journal of Physical Chemistry Letters, 2018, 9 (7), pp.1778-1782. 10.1021/acs.jpclett.8b00399 . hal-01868390

\section{HAL Id: hal-01868390 https://hal.science/hal-01868390}

Submitted on 5 Sep 2018

HAL is a multi-disciplinary open access archive for the deposit and dissemination of scientific research documents, whether they are published or not. The documents may come from teaching and research institutions in France or abroad, or from public or private research centers.
L'archive ouverte pluridisciplinaire HAL, est destinée au dépôt et à la diffusion de documents scientifiques de niveau recherche, publiés ou non, émanant des établissements d'enseignement et de recherche français ou étrangers, des laboratoires publics ou privés. 


\title{
Resolving the Framework Position of Organic Structure-Directing Agents in Hierarchical Zeolites via Polarized Stimulated Raman Scattering
}

\author{
Guillaume Fleury, ${ }^{\dagger}$ J Julian A. Steele, ${ }^{\dagger}$ Iann C. Gerber, ${ }^{\ddagger}$ F. Jolibois, ${ }^{\ddagger}$ P. Puech, ${ }^{\S}$ Koki Muraoka,
}

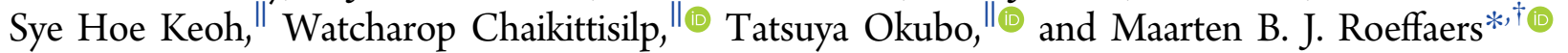

${ }^{\dagger}$ Department of Microbial and Molecular Systems, Centre for Surface Chemistry and Catalysis (COK), KU Leuven, Celestijnenlaan 200F, 3001 Leuven, Belgium

${ }^{\ddagger}$ LPCNO, Université Fédérale de Toulouse Midi-Pyrénées, INSA, CNRS, UPS, CNRS, 135 av. de Rangueil, F-31077 Toulouse, France

${ }^{\S}$ CEMES, Université de Toulouse, CNRS, 29, rue Jeanne Marvig, 31055 Toulouse, France

"Department of Chemical System Engineering, The University of Tokyo, 7-3-1 Hongo, Bunkyo-ku, Tokyo 113-8656, Japan

Supporting Information

ABSTRACT: The direct synthesis of hierarchically intergrown silicalite-1 can be achieved using a specific diquaternary ammonium agent. However, the location of these molecules in the zeolite framework, which is critical to understand the formation of the material, remains unclear. Where traditional characterization tools have previously failed, herein we use polarized stimulated Raman scattering (SRS) microscopy to resolve molecular organization inside few-micron-sized crystals. Through a combination of experiment and first-principles calculations, our investigation reveals the preferential location of the templating agent inside the linear pores of the MFI framework. Besides illustrating the attractiveness of SRS microscopy in the field of material science to study and spatially resolve local molecular distribution as well as orientation, these results can be exploited in the design of new templating agents for the preparation of hierarchical zeolites

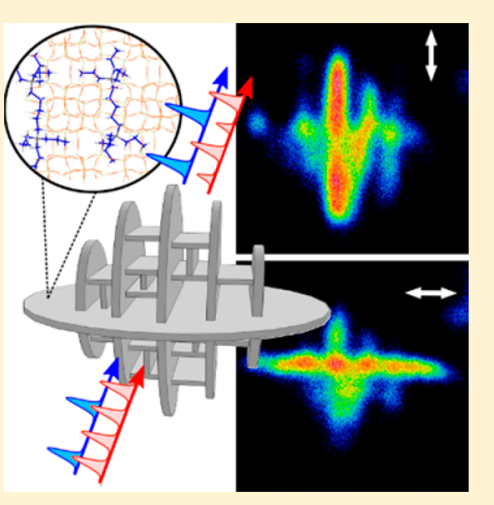

$\mathrm{Z}$ eolites are crystalline aluminosilicates that contain ordered micropores of molecular dimensions. ${ }^{1}$ This well-defined microporosity, together with the intrinsic ion-exchange properties of these materials, offers numerous applications ranging from shape-selective heterogeneous catalysis ${ }^{2,3}$ and gas separation $^{4,5}$ to housing stable luminescent Ag nanoclusters. ${ }^{6}$ However, this microporosity comes at the expense of efficient molecular transport within the material, which can be detrimental in catalytic applications. Several approaches have been put forward to reduce the diffusion path lengths within zeolites crystals, while keeping its well-ordered microporous structure. $^{7}$ Among these, the hierarchization of zeolites, that is, the introduction of an additional porosity level (typically mesopores), ${ }^{8}$ has been shown to be an efficient and viable solution from lab scale ${ }^{9-12}$ to industrial plant. ${ }^{13}$ Hierarchical zeolites can be prepared either by postsynthetic treatment (topdown approach) or direct synthesis (bottom-up approach). ${ }^{7}$ The former consists of the partial removal of silicon or aluminum atoms or the restructuration of the crystals, whereas the latter is achieved by using specific templating agents during the zeolite synthesis. To this end, both hard (e.g., nanostructured carbon) and soft (small organic compounds) templates can be used as structure-directing agents.
While some soft templating agents have a complex amphiphilic structure composed of a long hydrophobic chain and a hydrophilic zeolite structure-directing group, ${ }^{14}$ it was shown that much simpler compounds such as tetrabutylammonium and tetrabutylphosphonium can fulfill this role. ${ }^{15,16}$ Chaikittisilp et al. ${ }^{17}$ recently explored an alternative approach based on diquaternary cations of the type $\left(\mathrm{C}_{n} \mathrm{H}_{2 n+1}\right)_{3} \mathrm{~N}^{+}\left(\mathrm{CH}_{2}\right)_{k} \mathrm{~N}^{+}\left(\mathrm{C}_{n} \mathrm{H}_{2 n+1}\right)_{3}$, which were previously used in the preparation of silicalite- 1 membranes ${ }^{18}$ as the organic structure-directing agents (OSDAs) for the bottom-up preparation of hierarchical silicalite-1 zeolites. Out of the several OSDAs with different spacer and headgroup lengths that were investigated, only $\left(\mathrm{C}_{3} \mathrm{H}_{7}\right)_{3} \mathrm{~N}^{+}\left(\mathrm{CH}_{2}\right)_{5} \mathrm{~N}^{+}\left(\mathrm{C}_{3} \mathrm{H}_{7}\right)_{3}$ (shown in Figure $1 \mathrm{a}$, denoted hereafter $\mathrm{Pr}_{6}$-diquat- $\mathrm{C}_{5}$ ) directed the formation of hierarchical silcalite-1 zeolite (Figure 1b), while the others led to the formation of crystals with a more conventional morphology. ${ }^{19}$ The crystals prepared with $\operatorname{Pr}_{6}$ diquat- $\mathrm{C}_{5}$ consist of orthogonal silicalite-1 lamellae with a thickness of tens of nanometers (Figure 2a). For the sake of clarity, we will focus in this report on the two main types of

Received: February 7, 2018

Accepted: March 22, 2018

Published: March 22, 2018 

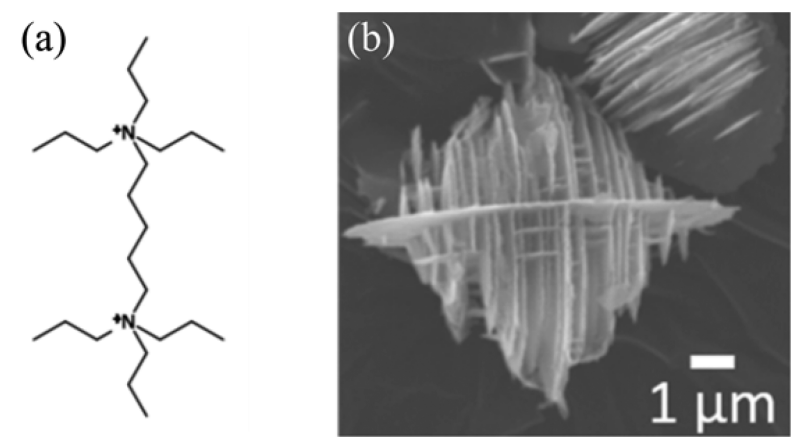

Figure 1. (a) Chemical structure of $\mathrm{Pr}_{6}$-diquat- $\mathrm{C}_{5}$. (b) SEM image of a typical hierarchically intergrown silicalite-1 crystal obtained using $\operatorname{Pr}_{6}$ diquat- $\mathrm{C}_{5}$ as a templating agent.
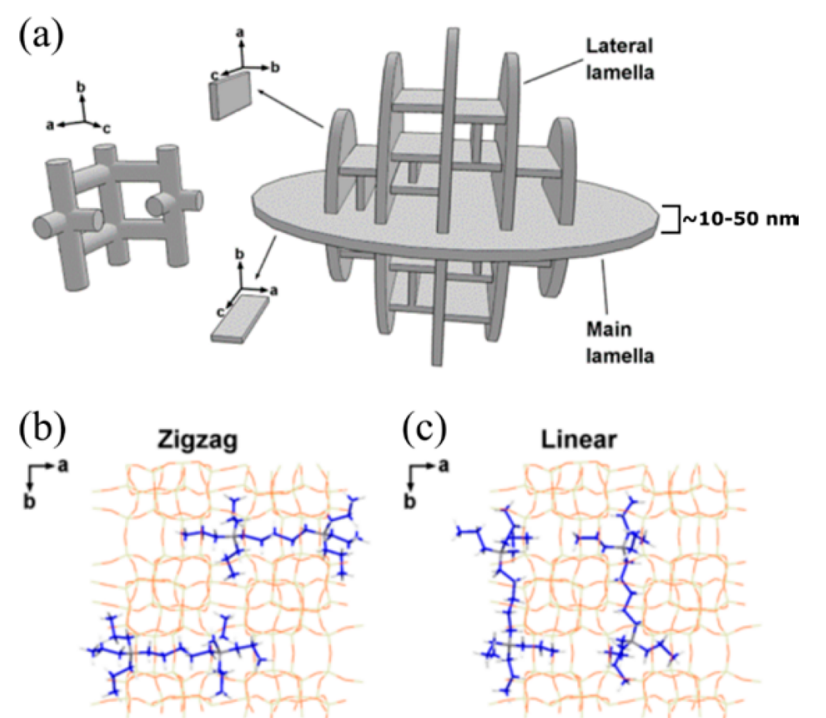

Figure 2. (a) Schematic illustration of the MFI framework and a hierarchically intergrown zeolite. (b) Optimized structures of the $\operatorname{Pr}_{6}$ diquat- $\mathrm{C}_{5} /$ silicalite- 1 complexes when the spacer of the molecules is located in the zigzag and linear pores, respectively. The axes indicate the crystallographic axis of the MFI framework.

lamellae, that is the main lamella and the lateral lamellae. TEM images coupled to selected area electron diffraction patterns of the lamellae confirmed the single-crystalline nature of the material and revealed that the crystallographic $b$ axis of the MFI framework runs perpendicular to the surface of each lamella. ${ }^{17}$ Additional HR-TEM imaging confirmed this observation and allowed us to observe line defects that were attributed to the intersection between two orthogonal intergrowths. ${ }^{19}$ While the orientation of the observed defects is not clear, their presence suggests that the orthogonal intergrowths originate from structure distortion rather than MFI-MEL intergrowths, as reported in silicalite-1 nanosheets; the absence of the MEL phase in the PXRP patterns, especially at $2 \theta=44-46^{\circ}$, supports this explanation. ${ }^{17}$

The hierarchically intergrown morphology obtained with $\mathrm{Pr}_{6}$ diquat- $\mathrm{C}_{5}$ was rationalized in terms of its unique fit within the zeolite. Silicalite-1 has a crystalline framework of the MFI type, which consists of interconnected zigzag (or "sinusoidal") and linear (or "straight") pores running along the crystallographic $a$ and $b$ axes, respectively. On the basis of the chemical structure of the OSDA and the structure of the MFI framework, the spacer linking the two quaternary ammonium groups can be in either the zigzag or linear pores (Figure 2b). A theoretical comparison of the two scenarios based on molecular dynamics and stabilization energy calculations showed that the arrangement of $\operatorname{Pr}_{6}$-diquat- $\mathrm{C}_{5}$ inside the linear pores is more favorable. ${ }^{19}$ However, further experimental proofs are desired to confirm those results.

To address this, characterization of the molecular organization at the single crystal is required. Accurate determination of the location of templating agent inside ZSM-5 crystals has been done using $\mathrm{X}$-ray diffraction, ${ }^{20}$ but this is not feasible in this case due to the small size of the zeolite particles. Imaging techniques relying on fluorescence ${ }^{21,22}$ or second harmonic generation $^{23}$ were also successfully used to probe molecular orientation in large zeolite crystals but are not applicable to $\mathrm{Pr}_{6}$ diquat- $\mathrm{C}_{5}$ owing to its intrinsic electronic properties. On the contrary, Raman spectroscopy has been used to investigate similar organic templates occluded inside zeolite crystals. ${ }^{24,25}$ Furthermore, polarized Raman imaging has proven to be extremely useful to assess molecular orientations in biological samples $^{26,27}$ as well as inorganic materials ${ }^{28,29}$ by utilizing the well-defined polarization dependence of vibrational signatures. In this contribution we use stimulated Raman scattering (SRS) microscopy to record the polarized images because it offers diffraction-limited resolution as well as fast acquisition times when looking at specific vibrations. ${ }^{30}$ Moreover, this technique is background-free and does not suffer from vibrational shifts unlike the more often used coherent anti-Stokes Raman scattering (CARS) microscopy simplifying data analysis.

Figure 3a presents the spontaneous Raman spectrum of $\mathrm{Pr}_{6}$ diquat- $\mathrm{C}_{5}$ occluded in the hierarchical silicalite- 1 zeolite in the $\mathrm{CH}$-stretching region. Partial overlap of bands corresponds to symmetric and asymmetric stretching of both $\mathrm{CH}_{2}$ and $\mathrm{CH}_{3}$ groups of $\operatorname{Pr}_{6}$-diquat- $\mathrm{C}_{5}$, leading to a complex pattern. The spectra of saturated aliphatic chains in this region are often subdivided into four contributions attributed in ascending order of wavenumbers to $\mathrm{v}_{\mathrm{s}}\left(\mathrm{CH}_{2}\right), \mathrm{v}_{\mathrm{s}}\left(\mathrm{CH}_{3}\right), \mathrm{v}_{\mathrm{as}}\left(\mathrm{CH}_{2}\right)$, and $\mathrm{v}_{\mathrm{as}}\left(\mathrm{CH}_{3}\right) .{ }^{31}$ Using this simplified picture, the band centered around $2884 \mathrm{~cm}^{-1}$ is therefore assigned to the symmetric stretching of $\mathrm{CH}_{2}$. It appears that unlike the other contributions at higher wavenumbers that are strongly overlapped, this particular band is well-resolved, meaning that this vibrational mode can be selectively probed with SRS microscopy. To provide deeper insights into the contributions in this spectral window, the Raman spectrum of a free $\operatorname{Pr}_{6}$-diquat- $\mathrm{C}_{5}$ molecule was calculated by density functional theory (DFT); see the computational details below. In our approach, we have first sampled the structures of $\mathrm{Pr}_{6}$-diquat- $\mathrm{C}_{5}$ molecules inside an MFI zeolite in both the linear and zigzag pores using molecular dynamics simulations and further force-field optimization (Figure 2b). Extracting free molecules (i.e., without the zeolite framework) from these two structures, DFT geometry optimizations have been performed that obviously lead to the same atomic positions. The Raman spectrum of the free molecule was then determined by DFT calculations (Figure 3a). A detailed analysis of the different modes observed in the simulated spectrum shows that the mode at the lowest wavenumber in the spectral window indeed corresponds to the symmetric stretching of some $\mathrm{CH}_{2}$ groups but not all of them; the calculated value of the wavenumber associated with this normal mode is $2915 \mathrm{~cm}^{-1}, 30 \mathrm{~cm}^{-1}$ higher than the experiment. Furthermore, the results of the simulation indicate that only the $\mathrm{CH}_{2}$ groups located on the spacer between the two quaternary ammonium contribute to this mode (Figure 


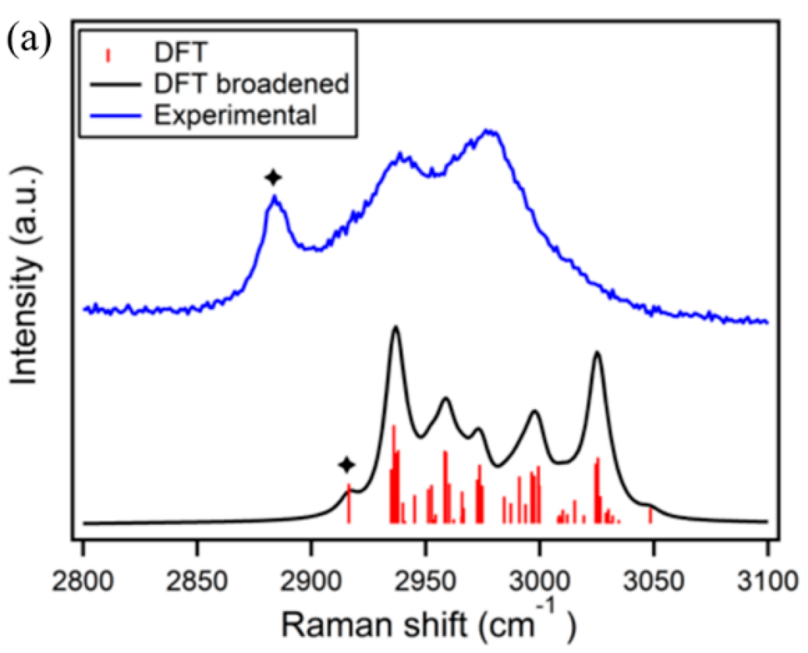

(b)
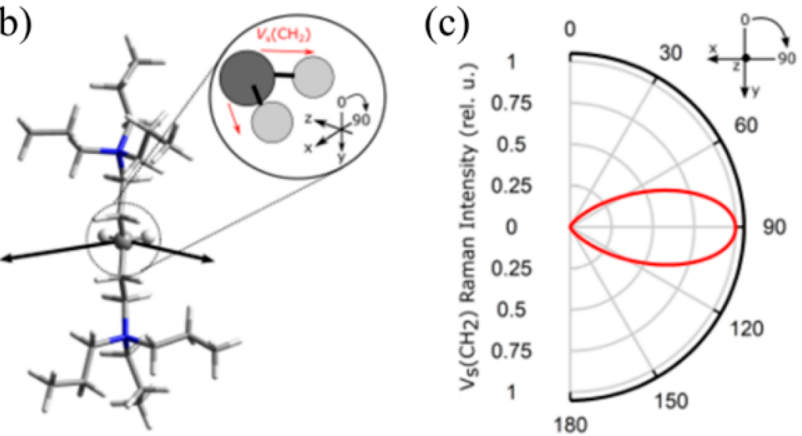

Figure 3. (a) Spontaneous Raman spectrum of Pr6-diquat-C5 in a MFI zeolite and theoretical spectra (discrete and broadened using Lorentzians with a fwhm of $5 \mathrm{~cm}^{-1}$ ) of the free molecule having an optimized geometry simulated by DFT calculations. (b) Illustration of the $\mathrm{CH}_{2}$ stretching vibrational mode of the theoretical spectrum. The arrows drawn on the molecule and the schematic representation of the $\mathrm{CH}_{2}$ group indicate the atomic motions associated with the vibrational mode. (c) Normalized polarization dependence of the vibrational mode depicted in panel $b$, with angles relative to the axis formed by the spacer (indicated by the $y$ axis).

$3 b)$, while the bands associated with the other $\mathrm{CH}_{2}$ groups appear at higher wavenumbers due to coupling with the terminal $\mathrm{CH}_{3}$ groups. The first mode in the $\mathrm{CH}$-stretching region can thus be used to assess the orientation of methylene groups located on the spacer and therefore the orientation of $\mathrm{Pr}_{6}$-diquat- $\mathrm{C}_{5}$ inside the pores of the hierarchical zeolite. Using the linear polarizability derivatives with respect to the normal modes the polarization dependence of the SRS signal corresponding to this specific vibrational mode was then computed. Assuming a propagation of the linear polarized excitation source perpendicular to the $\operatorname{Pr}_{6}$-diquat- $\mathrm{C}_{5}$ molecule depicted in Figure $3 \mathrm{~b}$, the angular dependence of the SRS signal intensity for this OSDA was calculated for different angles with respect to the axis formed by the spacer, with the results presented in Figure 3c. As expected, the polarization dependence of selected $\mathrm{v}_{\mathrm{s}}\left(\mathrm{CH}_{2}\right)$ vibration is highly anisotropic, reaching a maximum with the incident polarization parallel to the $\mathrm{CH}_{2}$ groups of the spacer (Figure 2c). A polarizationresolved mapping of this mode should therefore allow us to resolve the orientation of $\operatorname{Pr}_{6}$-diquat- $C_{5}$ molecules within the hierarchical zeolite, relative to the optical field of view and the crystal orientation.
Figure 4a presents a scanning electron microscope (SEM) image of a typical hierarchically intergrown silicalite-1 crystal.

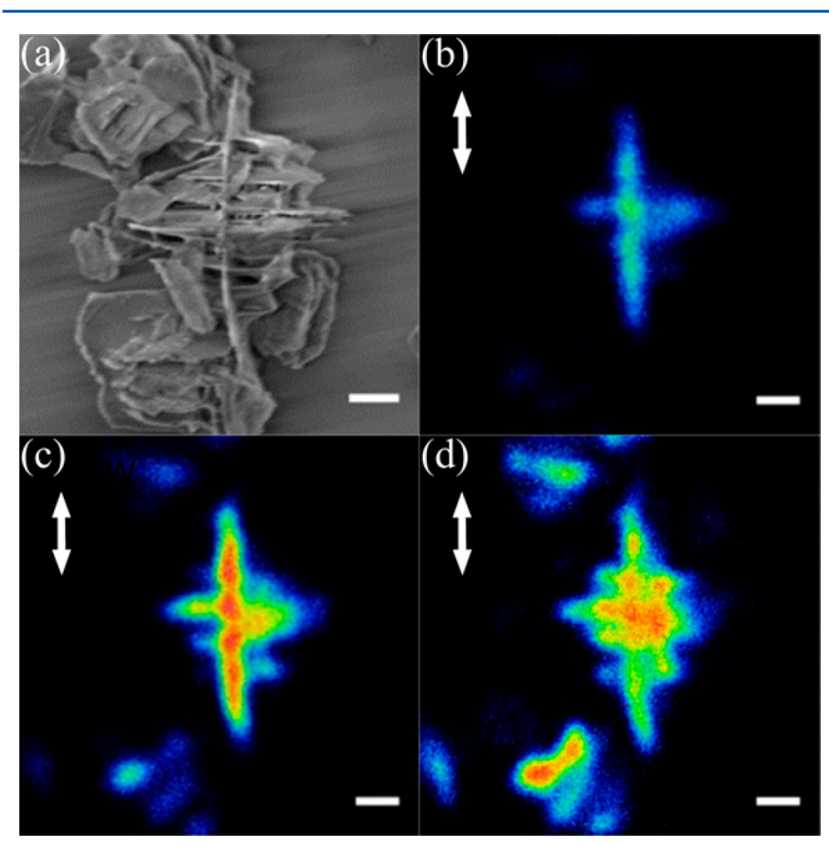

Figure 4. (a) SEM image of hierarchical silicalite- 1 crystals (scale bar = $1 \mu \mathrm{m})$. (b-d) SRS images at $2884 \mathrm{~cm}^{-1}$ of the OSDA molecules inside the micropores of the crystal, at 1,3 , and $5 \mu \mathrm{m}$ from the top of the crystal (scale bar $=1 \mu \mathrm{m}$ ). The excitation lasers have a linear polarization parallel to the main lamella (indicated by the arrow).

The correlative SRS imaging of this same crystal was recorded at different depths using the vibrational mode of $\operatorname{Pr}_{6}$-diquat- $\mathrm{C}_{5}$ molecules occluded in its microporous framework centered at $2884 \mathrm{~cm}^{-1}$ (Figure 5b,c). Because of the diffraction-limited
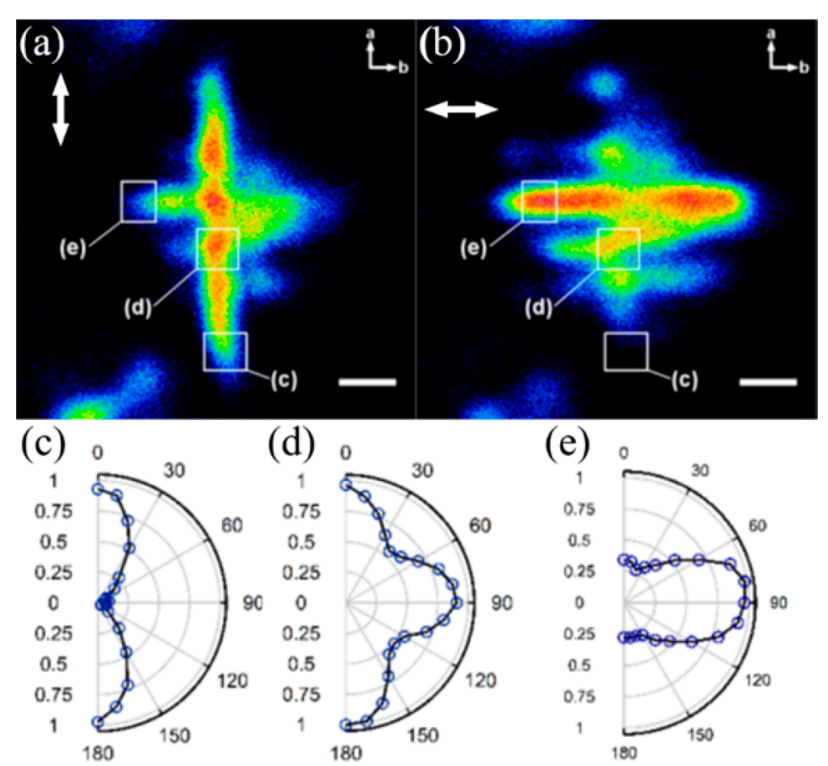

(d) 0
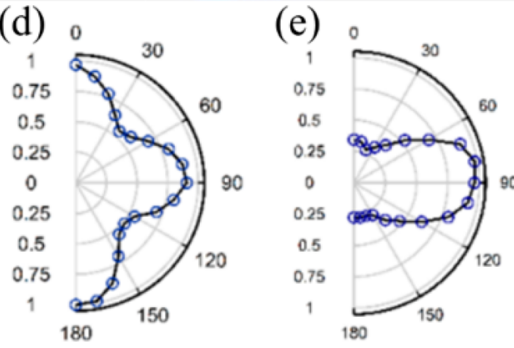

Figure 5. SRS images of the OSDA molecules inside the micropores of the crystal using linearly polarized laser beams (a) parallel to the $a$ axis of the main lamella and (b) perpendicular to the $a$ axis of the main lamella (the arrow indicates the polarization; scale bar $=1 \mu \mathrm{m}) .(\mathrm{c}, \mathrm{d})$ Intensity of the SRS signal in the three rectangular areas. (The angles are defined relative to the $a$ axis of the main lamella, indicated on the top right of the images.) 
resolution of the SRS microscope, the lamellae are slightly smeared in the image; however, the main lamella and the $90^{\circ}$ intergrowths can be easily distinguished. Thus the polarization dependence of the SRS signal can be evaluated at different locations in a single zeolite crystal.

The crystal of interest depicted in Figure $4 \mathrm{a}$ is lying on its side, with the main lamella perpendicular to the field of view (Figure 2a), meaning that the incident laser beams propagate through the crystal along the crystallographic $c$ axis of all lamellae. Polarization-resolved SRS imaging of the crystal using the band centered at $2884 \mathrm{~cm}^{-1}$ was done by varying the angle formed by the linear polarization of the laser beams and the crystallographic $a$ axis of the main lamella between 0 and $180^{\circ}$ by steps of $10^{\circ}$. Figure 5a,b shows the SRS images of the middle plane of the crystal for two polarization angles 0 and $90^{\circ}$ with respect to the crystallographic $a$ axis, respectively. Significant differences between the two images are clearly visible, with the SRS signal of the OSDA in the main lamella being more intense at $0^{\circ}$ than at $90^{\circ}$, whereas the opposite trend is observed for the lateral lamellae. For the three selected areas identified in Figure 5a,b, we plot the angular dependence of the SRS signal in Figure 5c-e. Here area (c) is selected along the central lamella with minimal intergrowths present, area (d) is also on the same central lamella, however, more toward the center and with a higher intergrowth content, and area (e) is chosen at the tip of the largest lateral lamella. These polar plots reveal the already observed anisotropic behavior, with areas (c) and (e) possessing a strong anisotropic signal, rotated by $90^{\circ}$, as could be expected for an intergrowth structure (see Figure $2 a)$. On the contrary, area (d) is composed of a mixture of both orthogonal components.

Considering the crystallographic structure of the main lamella and the simulated polar plots shown previously, the data in Figure $5 \mathrm{c}-\mathrm{e}$ indicate that the $\mathrm{CH}_{2}$ groups of the spacer are located inside the linear pores and that $\operatorname{Pr}_{6}$-diquat- $\mathrm{C}_{5}$ molecules are preferentially located in those pores of the MFI framework. Therefore, the remaining presence of SRS signal in the lateral regions in the middle of the crystal observed in Figure 5a originates from OSDA molecules located in smaller, secondary intergowths present on the lateral lamellae that are thus again parallel to the main lamella (Figure 4a). For the polar plot in Figure 5d, the presence of two components very close in intensity stems from the multiple $90^{\circ}$ intergrowths that are in focus at this location of the crystal, as shown on the SEM image of the crystal (Figure 4a).

In conclusion, we have demonstrated polarized SRS microscopy to be a powerful technique for the imaging of complex micron-sized zeolite crystals and resolve the orientation of ordered templating molecules within. Supported by DFT calculations of the $\operatorname{Pr}_{6}$-diquat- $C_{5}$ vibrational properties, the $\mathrm{v}_{\mathrm{s}}\left(\mathrm{CH}_{2}\right)$ mode and its polarization behavior were utilized to derive the relative alignment of the whole molecule within the hierarchical silicalite-1 zeolite. Our results show that the structure-directing agent is preferentially located in the linear pores rather than in the zigzag pores of the zeolite, in agreement with previous stabilization energy calculation. These insights can be exploited to design new dimeric OSDAs that can direct the formation of hierarchically intergrown zeolites by including in the chemical structure a spacer, which will have to be stretched to fit between two pores intersection. We note that while SRS microscopy has almost exclusively been used in biomedical studies up to now, the results obtained here endorse its strong potential in the fields material science to study and spatially resolve local molecular distribution as well as orientation.

\section{ASSOCIATED CONTENT}

\section{S Supporting Information}

The Supporting Information is available free of charge on the ACS Publications website at DOI: 10.1021/acs.jpclett.8b00399. Description of the experimental details (PDF)

\section{AUTHOR INFORMATION}

\section{Corresponding Author}

*E-mail: maarten.roeffaers@kuleuven.be. ORCID

Guillaume Fleury: 0000-0001-9480-3952

Julian A. Steele: 0000-0001-7982-4413

Iann C. Gerber: 0000-0001-5091-2655

Watcharop Chaikittisilp: 0000-0002-3240-0821

Tatsuya Okubo: 0000-0002-1681-0193

Maarten B. J. Roeffaers: 0000-0001-6582-6514

Notes

The authors declare no competing financial interest.

\section{ACKNOWLEDGMENTS}

We acknowledge financial support from the Research Foundation-Flanders (FWO, G.0962.13, AKUL/15/15 G0H0816N), KU Leuven Research Fund (C14/15/053, OT/ 12/059), and the Hercules foundation (HER/11/14). The research leading to these results has received funding from the European Research Council under the European Union's Seventh Framework Pro-gramme (FP/2007-2013)/ERC grant agreement no. [307523], ERC-Stg LIGHT to M.B.J.R. I.C.G and F.J. thank the Calcul en Midi-Pyrénées initiative-CALMIP (Project p0758) for allocation of computational time. W.C. thanks the Japan Society for the Promotion of Science (JSPS) for financial support (a Grant-in-Aid for Young Scientists (B): 16K18284). K.M. is a JSPS research fellow (DC1) and is supported by a JSPS Research Fellowship for Young Scientists (16J10484).

\section{REFERENCES}

(1) Weitkamp, J.; Puppe, L. Catalysis and Zeolites: Fundamentals and Applications; Springer: Berlin, 2013.

(2) Chen, N. Y.; Garwood, W. E. Industrial Application of ShapeSelective Catalysis. Catal. Rev.: Sci. Eng. 1986, 28 (2-3), 185-264.

(3) Csicsery, S. M. Shape-Selective Catalysis in Zeolites. Zeolites 1984, 4 (3), 202-213.

(4) Jensen, N. K.; Rufford, T. E.; Watson, G.; Zhang, D. K.; Chan, K. I.; May, E. F. Screening Zeolites for Gas Separation Applications Involving Methane, Nitrogen, and Carbon Dioxide. J. Chem. Eng. Data 2012, 57 (1), 106-113.

(5) Kosinov, N.; Gascon, J.; Kapteijn, F.; Hensen, E. J. M. Recent Developments in Zeolite Membranes for Gas Separation. J. Membr. Sci. 2016, 499, 65-79.

(6) Coutiño-Gonzalez, E.; Baekelant, W.; Steele, J. A.; Kim, C. W.; Roeffaers, M. B. J.; Hofkens, J. Silver Clusters in Zeolites: From SelfAssembly to Ground-Breaking Luminescent Properties. Acc. Chem. Res. 2017, 50 (9), 2353-2361.

(7) Pérez-Ramírez, J.; Christensen, C. H.; Egeblad, K.; Christensen, C. H.; Groen, J. C. Hierarchical Zeolites: Enhanced Utilisation of Microporous Crystals in Catalysis by Advances in Materials Design. Chem. Soc. Rev. 2008, 37 (11), 2530.

(8) Lakes, R. Materials with Structural Hierarchy. Nature 1993, 361, 511 . 
(9) Schmidt, F.; Lohe, M. R.; Büchner, B.; Giordanino, F.; Bonino, F.; Kaskel, S. Improved Catalytic Performance of Hierarchical ZSM-5 Synthesized by Desilication with Surfactants. Microporous Mesoporous Mater. 2013, 165, 148-157.

(10) Meunier, F. C.; Verboekend, D.; Gilson, J.-P.; Groen, J. C.; Pérez-Ramírez, J. Influence of Crystal Size and Probe Molecule on Diffusion in Hierarchical ZSM-5 Zeolites Prepared by Desilication. Microporous Mesoporous Mater. 2012, 148 (1), 115-121.

(11) Lakiss, L.; Ngoye, F.; Canaff, C.; Laforge, S.; Pouilloux, Y.; Qin, Z.; Tarighi, M.; Thomas, K.; Valtchev, V.; Vicente, A.; et al. On the Remarkable Resistance to Coke Formation of Nanometer-Sized and Hierarchical MFI Zeolites during Ethanol to Hydrocarbons Transformation. J. Catal. 2015, 328, 165-172.

(12) Schmidt, F.; Hoffmann, C.; Giordanino, F.; Bordiga, S.; Simon, P.; Carrillo-Cabrera, W.; Kaskel, S. Coke Location in Microporous and Hierarchical ZSM-5 and the Impact on the MTH Reaction. J. Catal. 2013, 307, 238-245.

(13) García-Martínez, J.; Li, K.; Krishnaiah, G. A Mesostructured Y Zeolite as a Superior FCC Catalyst - from Lab to Refinery. Chem. Commun. 2012, 48 (97), 11841.

(14) Choi, M.; Na, K.; Kim, J.; Sakamoto, Y.; Terasaki, O.; Ryoo, R. Stable Single-Unit-Cell Nanosheets of Zeolite MFI as Active and Long-Lived Catalysts. Nature 2009, 461 (7261), 246-249.

(15) Zhang, X.; Liu, D.; Xu, D.; Asahina, S.; Cychosz, K. A.; Agrawal, K. V.; Al Wahedi, Y.; Bhan, A.; Al Hashimi, S.; Terasaki, O.; et al. Synthesis of Self-Pillared Zeolite Nanosheets by Repetitive Branching. Science 2012, 336 (6089), 1684.

(16) Xu, D.; Swindlehurst, G. R.; Wu, H.; Olson, D. H.; Zhang, X.; Tsapatsis, M. On the Synthesis and Adsorption Properties of SingleUnit-Cell Hierarchical Zeolites Made by Rotational Intergrowths. Adv. Funct. Mater. 2014, 24 (2), 201-208.

(17) Chaikittisilp, W.; Suzuki, Y.; Mukti, R. R.; Suzuki, T.; Sugita, K.; Itabashi, K.; Shimojima, A.; Okubo, T. Formation of Hierarchically Organized Zeolites by Sequential Intergrowth. Angew. Chem., Int. Ed. 2013, 52 (12), 3355-3359.

(18) Lai, Z.; Bonilla, G.; Diaz, I.; Nery, J. G.; Sujaoti, K.; Amat, M. A.; Kokkoli, E.; Terasaki, O.; Thompson, R. W.; Tsapatsis, M.; et al. Microstructural Optimization of a Zeolite Membrane for Organic Vapor Separation. Science 2003, 300 (5618), 456.

(19) Keoh, S. H.; Chaikittisilp, W.; Muraoka, K.; Mukti, R. R.; Shimojima, A.; Kumar, P.; Tsapatsis, M.; Okubo, T. Factors Governing the Formation of Hierarchically and Sequentially Intergrown MFI Zeolites by Using Simple Diquaternary Ammonium StructureDirecting Agents. Chem. Mater. 2016, 28 (24), 8997-9007.

(20) Van Koningsveld, H.; Van Bekkum, H.; Jansen, J. C. On the Location and Disorder of the Tetrapropylammonium (TPA) Ion in Zeolite ZSM-5 with Improved Framework Accuracy. Acta Crystallogr., Sect. B: Struct. Sci. 1987, 43 (2), 127-132.

(21) Kubarev, A. V.; Breynaert, E.; Van Loon, J.; Layek, A.; Fleury, G.; Radhakrishnan, S.; Martens, J.; Roeffaers, M. B. J. Solvent PolarityInduced Pore Selectivity in H-ZSM-5 Catalysis. ACS Catal. 2017, 7 (7), 4248-4252.

(22) Hendriks, F. C.; Schmidt, J. E.; Rombouts, J. A.; Lammertsma, K.; Bruijnincx, P. C. A.; Weckhuysen, B. M. Probing Zeolite Crystal Architecture and Structural Imperfections Using Differently Sized Fluorescent Organic Probe Molecules. Chem. - Eur. J. 2017, 23 (26), 6305-6314.

(23) van der Veen, M. A.; Sels, B. F.; De Vos, D. E.; Verbiest, T. Localization of $p$-Nitroaniline Chains Inside Zeolite ZSM-5 with Second-Harmonic Generation Microscopy. J. Am. Chem. Soc. 2010, 132 (19), 6630-6631.

(24) Brémard, C.; Laureyns, J.; Patarin, J. Polarized Single-Crystal Micro-RamanSpectroscopy of As-Synthesized Silicalite-1,Al MFI- and Fe MFI-Type Zeolites. J. Raman Spectrosc. 1996, 27 (6), 439-445.

(25) Schmidt, J. E.; Fu, D.; Deem, M. W.; Weckhuysen, B. M. Template-Framework Interactions in Tetraethylammonium-Directed Zeolite Synthesis. Angew. Chem., Int. Ed. 2016, 55 (52), 16044-16048. (26) Kennedy, A. P.; Sutcliffe, J.; Cheng, J.-X. Molecular Composition and Orientation in Myelin Figures Characterized by
Coherent Anti-Stokes Raman Scattering Microscopy. Langmuir 2005, 21 (14), 6478-6486.

(27) Bioud, F.-Z.; Gasecka, P.; Ferrand, P.; Rigneault, H.; Duboisset, J.; Brasselet, S. Structure of Molecular Packing Probed by PolarizationResolved Nonlinear Four-Wave Mixing and Coherent Anti-Stokes Raman-Scattering Microscopy. Phys. Rev. A: At., Mol., Opt. Phys. 2014, 89 (1), 013836.

(28) Domke, K. F.; Day, J. P. R.; Rago, G.; Riemer, T. A.; Kox, M. H. F.; Weckhuysen, B. M.; Bonn, M. Host-Guest Geometry in Pores of Zeolite ZSM-5 Spatially Resolved with Multiplex CARS Spectromicroscopy. Angew. Chem., Int. Ed. 2012, 51 (6), 1343-1347.

(29) Liu, K.-L.; Kubarev, A. V.; Van Loon, J.; Uji-i, H.; De Vos, D. E.; Hofkens, J.; Roeffaers, M. B. J. Rationalizing Inter- and Intracrystal Heterogeneities in Dealuminated Acid Mordenite Zeolites by Stimulated Raman Scattering Microscopy Correlated with SuperResolution Fluorescence Microscopy. ACS Nano 2014, 8 (12), $12650-12659$.

(30) Freudiger, C. W.; Min, W.; Saar, B. G.; Lu, S.; Holtom, G. R.; He, C.; Tsai, J. C.; Kang, J. X.; Xie, X. S. Label-Free Biomedical Imaging with High Sensitivity by Stimulated Raman Scattering Microscopy. Science 2008, 322 (5909), 1857.

(31) Workman, J. The Concise Handbook Of Analytical Spectroscopy: Theory, Applications, and Reference Materials; World Scientific Publishing Company: Singapore, 2016. 